\title{
Production of Gold-198 Grains
}

\section{Hisashi Kato}

Japan Atomic Energy Research Institute, Ibaraki-ken, Japan

It is now about 25 years since radon in the form of 'radon seeds' began to be replaced by the 198radioisotope of gold $\left({ }_{79}^{198} \mathrm{Au}\right)$ as a radiation source in the treatment of malignant diseases. The gold-198 is produced by irradiation of metallic gold $\left({ }_{79}^{197} \mathrm{Au}\right)$ with thermal neutrons, whilst enclosed in a sheath of platinum. The platinum capsules containing the gold-198 are known as 'gold grains' and are made (1) in large numbers by various producers. One of these is the Japan Atomic Energy Research Institute (JAERI) at which production was started $(2,3)$ in 1976 using the JRR-2 and JRR-4 reactors.

\section{Properties of Gold-198}

Although many factors characterize a radioisotope, half-life, $\gamma$-ray energy and yield of activity are the important ones for radiation therapy. Gold-198 decays with a half-life of 2.7 days to stable mercury- 198 by emission of $\beta$ particles of maximum energy 0.960 Mev and $\gamma$-rays of energies $0.412,0.68$ and 1.09 $\mathrm{Mev}$ as shown schematically in Figure 1, In a gold grain, the thickness of the enveloping sheath of platinum is such that the $\beta$ particles, but not the $\gamma$-rays, are absorbed.

The energy $(0.412 \mathrm{Mev})$ of the most abundant $\gamma$-rays is suited for internal irradiation of human organs, but the use of gold-198 is limited to shortterm applications because of its rather short half-life.

\section{The Gold Grains}

As produced for irradiation at the JAERI, a gold grain consists of a gold cylinder (diameter $0.5 \mathrm{~mm}$, length $2.5 \mathrm{~mm}$, mass $8.7 \mathrm{mg}$ ) enclosed in a platinum tube (inner diameter $0.5 \mathrm{~mm}$, outer diameter $0.8 \mathrm{~mm}$, length $2.5 \mathrm{~mm}$, mass $11.0 \mathrm{mg}$ ). The ends of both the platinum tube and the gold cylinder are electroplated with platinum to a thickness of $0.05 \mathrm{~mm}$. For irradiation, the grains are loaded into aluminium tubes (inner diameter $0.9 \mathrm{~mm}$, outer diameter $2.5 \mathrm{~mm}$, length $38 \mathrm{~mm}$ ). Each tube contains fourteen grains(Figure 2).

\section{Neutron Irradiation of the Grains}

A target is assembled by enclosing the aluminium tubes containing the gold grains in an aluminium irradiation capsule with an aluminium spacer. The use of high purity aluminium minimises the formation during irradiation of undesirable long-lived radioisotopes from impurity elements. Four aluminium tubes ( 56 gold grains in total) are usually loaded in one irradiation capsule, which is coldwelded and tested for leaks by immersion in glycol under reduced pressure.

When the capsules are exposed to thermal neutrons gold-198 is produced from the natural gold-197 isotope by the reaction:

$$
{ }_{79}^{197} \mathrm{Au}+{ }_{0}^{1} \mathrm{n} \rightarrow{ }_{79}^{198} \mathrm{Au}+\gamma
$$

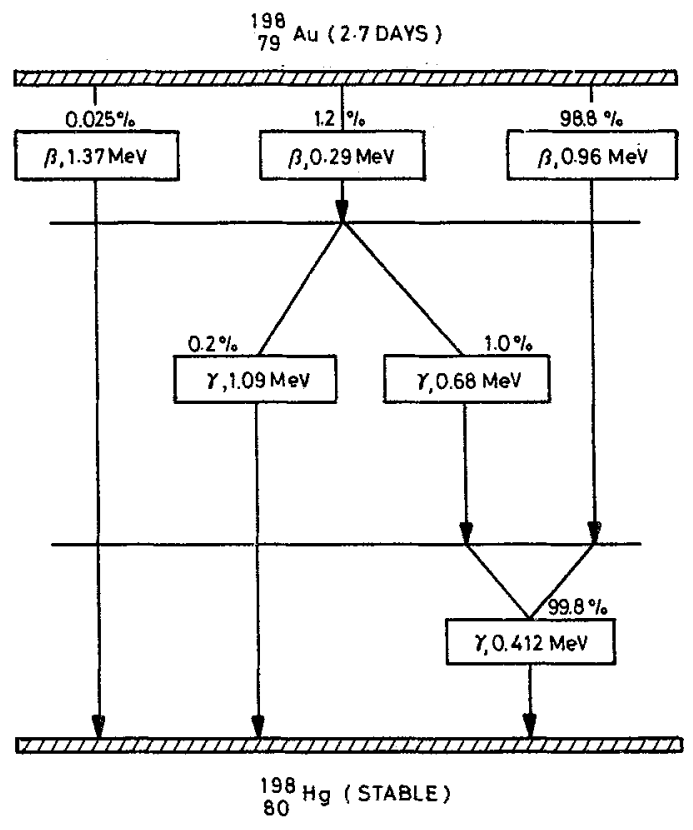

Fig. 1 Disintegration scheme of gold-198

Irradiation Conditions for the Preparation of Gold-198 and Resulting Activity of Gold Grains

\begin{tabular}{c|c|c|c|c}
\hline Reactor & $\begin{array}{c}\text { Irradiation } \\
\text { time } \\
\text { hours }\end{array}$ & $\begin{array}{c}\text { Thermal neutron } \\
\text { flux } \\
\text { neutron } / \mathrm{cm}^{2} / \mathrm{s}\end{array}$ & $\begin{array}{c}\text { Activity after } \\
\text { irradiation } \\
\mathrm{mCi} / \mathrm{grain}\end{array}$ & $\begin{array}{c}\text { Activity at } \\
\text { time of use } \\
\mathrm{mCi} / \text { grain }\end{array}$ \\
\hline JRR-2 & 24 & $4.6 \times 10^{13}$ & 621 & 5.1 \\
JRR-2 & 1.75 & $4.5 \times 10^{13}$ & 50.2 & 5.2 \\
JRR-4 & $1=08$ & $5.3 \times 10^{13}$ & 29.3 & 5.2
\end{tabular}


The level of activity obtained when a target material is irradiated in a reactor can be estimated from the equation:

$$
\mathrm{S}=\frac{0.6 \sigma \phi\left(1-\mathrm{e}^{-0.6931 / \mathrm{T}}\right)}{3.7 \times 10^{10} \mathrm{~A}}
$$

where:

$S$ is the specific activity of the product in curies per gram of target element

$\sigma$ is the activation cross section of the target nuclide in barns

$\phi$ is the thermal neutron flux density in neutrons $/ \mathrm{cm}^{2} / \mathrm{s}$

$A$ is the atomic weight of the target element

$t$ is the irradiation time

$T$ is the half-life of the product radioisotope.

The radioactivity of each gold grain can therefore be adjusted and by choosing appropriate irradiation conditions it is controlled so that $5.0 \mathrm{mCi}$ are available at the time of use. Some examples of the irradiation conditions together with resulting activities are shown in the Table.

\section{Procedures after Irradiation}

The handling of the gold grains after irradiation is carried out in cells (4) with $10 \mathrm{~cm}$ thick lead shielding at the Radioisotope Production Laboratory (5). The irradiated capsules are decanned in a cell provided with a capsule opener, after which they are transferred to another cell to prevent possible radioactive contamination of the grains with radioisotopes induced in the aluminium capsules. Their activity is then checked before they are packed for despatch.

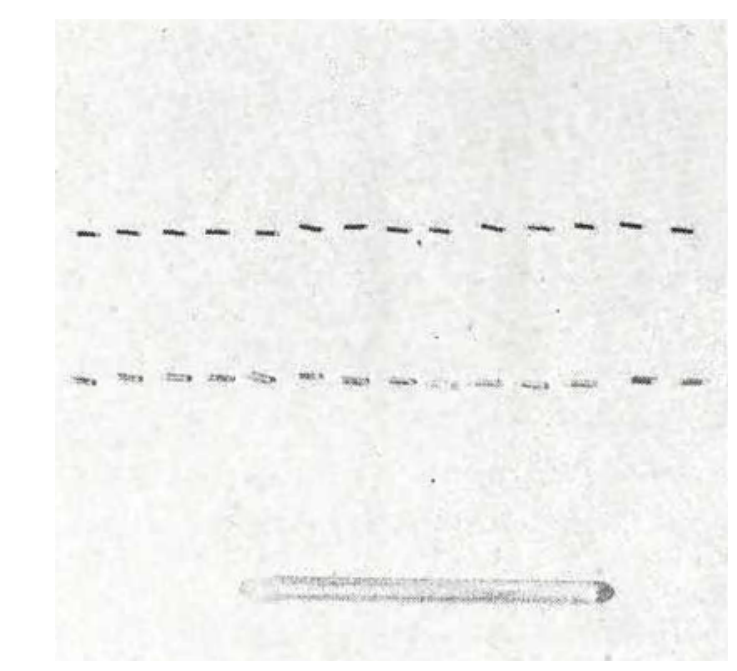

Fig. 2 Gold cylinders and platinum tubes used by JAERI for making gold grains. The grains are loaded into the aluminium tube for irradiation

\section{An Iron-Hardened Acid Gold Electrolyte}

During the Annual Conference of the Institute of Metal Finishing held in Torquay in May an interesting paper on the use of iron as opposed to cobalt or nickel as the hardener in acid gold cyanide electrolytes was presented jointly by Peter Kunz of Degussa, Schwäbisch Gmünd, and James Donohoe of M. L. Alkan, London.

Although iron in the form of potassium ferrocyanide was extensively used in the early days of gold plating, the more recent introduction of acid gold cyanide baths caused it to be regarded as an undersirable impurity, causing reduced ductility and increased stresses in the deposit. Iron is, however, similar to the widely used nickel and cobalt in so nany respects that such deleterious effects should not really be expected.

The investigation described in the paper was based upon a new range of acid hard gold electrolytes having high rates of deposition, employing iron, nickel and cobalt respectively as the hardening additions, with citric acid as the buffer, but including a group of (unnamed) heterocyclic compounds designed to give higher cathode efficiencies. The test pieces used were of polished brass with a nickel under- coat; cathode efficiency was determined by weighing before and after gold plating and thickness was assessed by betabackscatter, hardness by Zwick microhardness tester, and wear testing was also carried out.

All three hardening elements gave similar resuits, and all deposits were adherent with no blistering. The ironcontaining electrolyte gave the greatest increase in rate of deposition with increasing current density and also with increasing $\mathrm{pH}$, while it also showed the lowest values of internal stress. The average hardnesses obtained for the ironbearing deposits fell between those for the cobalt and nickel containing hard golds, while their resistance to wear was closely similar to that of the cobalt-hardened type but greatly superior to that of nickel-hardened gold. Solderability and porosity were found to be comparable on the deposits from all three electrolytes.

Thus no disadvantages were observed in using iron as the hardening element, while the authors also point out a unique advantage in that dissolved metal impurities can be precipitated out of solution by potassium ferrocyanide, any slight excess thereof being compatible with the electrolyte. 